\title{
Single Nucleotide Polymorphism Analysis of Pvmdr- 1 in Plasmodium Vivax Isolated From Military Personnel of Republic of Korea in 2016 and 2017
}

Jin-Jong Bong

Armed Forces Medical Research Institute

Wonsig Lee

Armed Forces Post Graduate Medical Institute Armed Forces Institute of Transfusion

Qu-Ehn Park

Armed Forces Medical Research Institute

Kyung Tae Noh ( $\nabla$ nkt2062@hanmail.net)

Armed Forces Medical Research Institute https://orcid.org/0000-0001-5534-5338

\section{Research}

Keywords: Plasmodium vivax, Multi-drug resistance protein 1, Single nucleotide polymorphism, Chemoprophylaxis

Posted Date: March 6th, 2021

DOl: https://doi.org/10.21203/rs.3.rs-273974/v1

License: (9) (1) This work is licensed under a Creative Commons Attribution 4.0 International License. Read Full License 


\section{Abstract}

Background: Malaria chemoprophylaxis using chloroquine and primaquine has been administered to resident soldiers in the $3^{\text {rd }}$ Army of Republic of Korea (ROK) to prevent malaria infection since the year 1997. Due to mass chemoprophylaxis against malaria, concern exists about occurrence of chloroquine resistance. Herein, we investigated the single nucleotide polymorphisms (SNPs) of the Plasmodium vivax multi-drug resistance protein-1 ( $P v m d r-1)$ gene to monitor the risk of chloroquine resistance.

Methods: To evaluate the risk of malaria chemoprophylaxis, SNPs of the Pvmdr-1 gene were analysed in 73 soldiers of the $3^{\text {rd }}$ Army of ROK diagnosed with infection by Plasmodium vivax.

Results: Quintuple mutations (G698S, L845F, M908L, T958M, and F1076L) were detected in 73 soldiers. Mutation in the Y541C position was detected in soldiers at a frequency of $1.3 \%$ (1/73). In addition, silent mutations were detected at positions 44K, 493L, 529T, and 1233E. Based on these SNPs, Pvmdr-1 sequences of ROK were classified into 6 haplotypes. Phylogenetic analysis showed that the neighbourhood of the 6 haplotypes were Chaina_NB-16 and Papua New Guinea-PNG58 (Figure 1).

Conclusions: Genetic- or phenotypic-based chloroquine resistance was not observed. However, various SNPs including a newly identified non-synonymous mutation (Y541C) have been introduced into Plasmodium vivax malaria endemic areas in ROK. Thus, to prevent the emergence of chloroquine resistance, continuous surveillance for SNPs of Pvmdr-1 related with chloroquine resistance is essential in the malaria chemoprophylaxis-executed regions of ROK.

\section{Background}

Annually, more than 300 million of the world`s population are infected with malaria, and about 500,000 people die from malaria. The re-emergence of $P$. vivax (Plasmodium vivax) malaria in ROK, which was supposed to eradicated, was reported in Paju City of Gyeonggi Province in 1993 [1, 2]. Infection first occurred in a soldier of the 3rd Army of ROK, and the incidence of malaria infections has been steadily increasing [3]. In ROK, P. vivax malaria endemic regions are localized near the demilitarized zone (DMZ; the border between ROK and the Democratic People's Republic of Korea, DPRK). Thus, soldiers and civilians residing in the DMZ have been classified as high-risk group for malaria infection. Among the total malaria patients in the ROK, soldiers and military veterans accounted for a large proportion. Because of this, members of the army of ROK have undergone prophylactic chemotherapy against malaria to prevent patient outbreak since 1997 [4]. The detailed procedure of chemoprophylaxis is as follows: 300 $\mathrm{mg}$ chloroquine is administered weekly to military personnel stationed near the DMZ from July to October for 15 weeks, and $15 \mathrm{mg}$ primaquine is administered daily for 2 weeks. Chloroquine is effective to eradicate $P$. vivax in asexual blood stages and gametocytes, and primaquine is responsible for killing the hypnozoite form of $P$. vivax parasite in the liver stage. Due to the risk of chloroquine resistance by massive and long-term use of chemoprophylaxis for prevention of malaria [5], the army of ROK has been monitoring drug resistance by analysing mutations in Pvmdr-7 (Plasmodium vivax drug resistance 
protein 1) [6]. To date, various chloroquine-resistant cases in several countries including Indonesia, Southeast Asia, India, and Central and South America have been reported [7-13]. The incidence of infectious diseases overseas is increasing, and there is concern about the influx of resistant malaria from Southeast Asian countries. Thus, genetic- and phenotypic-based research on chloroquine resistance is needed. There also is need for periodic monitoring of the genetic polymorphisms of Pvmdr-1.

\section{Methods}

\section{Ethics statement and sample preparation}

This study was approved by the ethics committee of the Armed Forces Medical Command (Approval No. AFMC-16067-IRB-16-056, September 2016). An approval form was used to obtain written informed consent and permission from each participant for providing a $5 \mathrm{ml}$ blood sample.

\section{Collection of clinical isolates}

Seventy-three blood samples from patients infected with malaria or malaria suspected patients with fever were collected in Armed Forces Hospitals near the DMZ located in northern Gyeonggi Province and in the northwest region of the ROK from 2016 to 2017. All patient samples with a history of fever in the 48 hours before their arrival at the hospitals were screened with a rapid diagnostic test (STANDARD DIAGNOSTICS Inc., USA), and blood smear test with microscopy.

\section{DNA extraction and nested PCR diagnosis}

Genomic DNA was extracted from 200 ul whole blood using DNeasy Blood and Tissue Kit (Qiagen, Hilden, Germany) as recommended by the manufacturer. Purified DNA samples were diagnosed by Nested PCR (polymerase chain reaction). For the amplification of purified DNA templates, using Master cycler nexus X2 thermal cycler (Eppendorf Inc., Germany) and specific primer sets [The first round of PCR primer sets: rPLU5 (TTA AAA TTG TTG CAG TTA AAA CG) AND rPLU6 (CCT GTT GTT GCC TTA AAC TTC), The second round of PCR primer sets: rVIV1 (CGC TTC TAG CTT AAT CCA CAT AAC TGA TAC) and rVIV2 (ACT TCC AAG CCG AAG CAA AGA AAG TCC TTA)], Nested PCR was conducted. The first round of PCR was performed under the following conditions: $94^{\circ} \mathrm{C}$ for $5 \mathrm{~min}$, followed by 30 cycles of $94^{\circ} \mathrm{C}$ for $30 \mathrm{sec}$, $60^{\circ} \mathrm{C}$ for $1 \mathrm{~min}$, and $72^{\circ} \mathrm{C}$ for $1 \mathrm{~min}$, and a final extension at $72^{\circ} \mathrm{C}$ for $5 \mathrm{~min}$. The second PCR was performed under the following conditions: $94^{\circ} \mathrm{C}$ for $5 \mathrm{~min}$, followed by 35 cycles of $94^{\circ} \mathrm{C}$ for $20 \mathrm{sec}, 60^{\circ} \mathrm{C}$ for $20 \mathrm{sec}$, and $72^{\circ} \mathrm{C}$ for $20 \mathrm{sec}$, and a final extension at $72^{\circ} \mathrm{C}$ for $5 \mathrm{~min}$. PCR products were analyzed on agarose gels of $1.5 \%$ by electrophoresis and visualized by Fluor Chem FC3 (PROTEIN SIMPLE, USA).

\section{Nested PCR, SNPs, and Phylogenetic tree analysis of Pvmdr-1}

The Pvmdr1 gene was amplified by nested PCR using specific primers (Table 1). The first round of PCR was performed under the following conditions: $94^{\circ} \mathrm{C}$ for $5 \mathrm{~min}$, followed by 30 cycles of $94^{\circ} \mathrm{C}$ for $30 \mathrm{sec}$, $56^{\circ} \mathrm{C}$ for $30 \mathrm{sec}$, and $72^{\circ} \mathrm{C}$ for $4.5 \mathrm{~min}$, and a final extension at $72^{\circ} \mathrm{C}$ for $10 \mathrm{~min}$. The second PCR was performed under the following conditions: $94^{\circ} \mathrm{C}$ for $5 \mathrm{~min}$, followed by 35 cycles of $94^{\circ} \mathrm{C}$ for $30 \mathrm{sec}, 57^{\circ} \mathrm{C}$ 
for $30 \mathrm{sec}$, and $72^{\circ} \mathrm{C}$ for $4 \mathrm{~min}$, and a final extension at $72^{\circ} \mathrm{C}$ for $10 \mathrm{~min}$. After the amplification, sequence analysis was performed by specific sequencing primers as shown in Table 1. Sequencing primers were designed to identify near full-length pvmdr1 gene (103-4356; 4253bp). Direct sequencing of PCR products was performed by using Big Dye Terminator v3.1 Cycle Sequencing Kit (Applied Biosystems, CA, USA), and the products were resolved on ABI 3730XL Genetic Analyzer (Applied Biosystems, CA, USA). Confirmed sequences were analyzed with a wild-type (AY571984.1; Pvmdr-1) and Plasmo DB (Plasmodb.org) parasite sequences using Bio Edit v7.0.5 software.

\section{Results}

\section{Nested PCR and SNP analyses of the Pvmdr-1 gene}

For SNP analysis of Pvmdr-1, we conducted nested PCR of 73 specimens, the positive of which were used in sequence analysis. As shown in Table 2, five non-synonymous mutations (G698S, L845F, M908L, T958M, and F1076L) were detected in all specimens (2016: 20/20, 2017: 53/53). Interestingly, a novel non-synonymous mutation (Y541C) was detected in 1 soldier at a frequency of $1.8 \%$ (2017: 1/53). In addition, silent mutations in 44K [2016: 4/20 (20\%), 2017: 24/53 (45.2\%)], 493L [2016: 5/20 (25\%), 2017: 14/53 (26.4\%)], 529T [2016: 15/20 (75\%), 2017: 30/53 (56.6\%)], and 1233E [2016: 8/20 (40\%), 2017: 30/53 (56.6\%) positions were detected in specimens. Alignment and mapping data of Pvmdr-1 wild-type and mutant-type sequences were provided (Additional File 1; Figure S1).

\section{Genotypic classification of the Pvmdr-1 gene}

As shown in Table 3, all specimens clustered into 6 groups from Type 0 to Type 5, and all haplotypes possesses 5 non-synonymous mutations (G698S, L845F, M908L, T958M, and F1076L). We genotypically classified the 6 haplotypes based on Pvmdr-1 sequences from 73 specimens in ROK from 2016 to 2017. Quintuple non-synonymous mutations (G698S, L845F, M908L, T958M, and F1076L) were detected in all types. Type 0 was found in 1 case in 2016, and there was no mutation other than the 5 non-synonymous mutations. For synonymous mutation, 44K mutant was found in Type $1(2016 ; 1 / 20,2017 ; 8 / 53)$ and Type $2(2016 ; 3 / 20,2017 ; 16 / 53)$, 529T mutant was found in Type $3(2016 ; 5 / 20,2017 ; 14 / 53)$, Type 4 (2016; 10/20, 2017; 14/53), and Type $5(2016 ; 0 / 20,2017$ 1/53), 1233E mutant was found in Type 2 $(2016 ; 3 / 20,2017 ; 16 / 53)$ and Type $3(2016 ; 5 / 20,2017 ; 14 / 53)$, and $493 \mathrm{~L}$ was only found in Type 3 $(2016 ; 5 / 20,2017 ; 14 / 53)$. Type $5(2017 ; 1 / 53)$ was nearly the same as Type 4 , except it harboured the first identified Y541C mutation. In the years 2016 and 2017, Type 4 (24/73) was abundant and showed a $100 \%$ match with the Pvmdr-1 sequence of North Korea.

\section{Phylogenetic analysis of the Pvmdr-1 gene}

We performed analysis of phylogenetic relationships with on overall Pvmdr-1 sequence and classified them into 6 haplotypes (Table 3). We used nearly full-length sequences (from 104 bp to 4290 bp) of Pvmdr-1 to perform phylogenetic relationship analysis. The analysed 6 haplotypes were clustering based on the MDR sequence in North Korea and were sorted into Type 0, Type 1, Type 2, Type 3, Type 4, and 
Type 5. Type 4 sequence was identical to the MDR sequence in North Korea. The neighbourhood types of 6 haplotypes were identified as Chaina_NB-16 and Papua New Guinea-PNG58 (Figure 1).

\section{Discussion}

In ROK, there is a $P$. vivax-based endemic area in Gyeonggi province near the $\mathrm{DMZ}$, indicating that the military personnel residing in this region are at high-risk of malaria. Since 1997, ROK Army has carried out continuous malaria chemoprophylaxis (chloroquine and primaquine) to prevent malaria against approximately 100,000 military personnel. Due to massive chemoprophylaxis, the concern of resistance is consistent.

Chloroquine and primaquine have been used worldwide as therapeutic and preventive drugs of malaria. Due to the extensive drug usage, drug insusceptibility has been reported, and studies have been performed on SNP investigation of relevant genes including Pvcrt and Pvmdr [14]. Since 1997, ROK Army has executed massive and long-term malaria chemoprophylaxis (Chloroquine, Primaquine) near the malaria endemic regions due to concern of chemoprophylaxis-mediated resistance. Thus, the Armed Forces Medical Research Institute has conducted SNP analysis on malaria resistance-related genes, since $2012[2,6]$. To date, although there have been $P$. vivax cases of resistance to chloroquine in many other areas of the world, in malaria-endemic regions of ROK, drug resistance has not been reported. However, issues including drug insusceptibility to chloroquine and rapid transition of PvmdrSNPs have been reported. A previous study showed that Pvmdr SNP mutations of T529 (56.4\%), F1076L (100\%), E1233 (40\%), and S1358 (3.7\%) were identified in ROK army from 2011 to 2012 [6; Chung et al., 2015].

In this study, SNP profiling is dramatically changed compared with previous ROK reports. In detail, G698S, L845F, M908L, T958M, F1076L, Y541C, K44, L493, and T529 mutations in the Pvmdr-1 gene were detected in malaria-infected military personnel of ROK. Previous reports showed the F1076L mutation in the Pvmdr-1 gene in India and Afghanistan people $[15,16]$. It was also reported that the F1076L mutation in the Pvmdr-1 gene has a relationship with chemoprophylaxis. For example, the high prevalence of Pvmdr-1 F1076L mutation might have influenced the efficacy of chloroquine combination with primaquine in Iran from 2001 to 2016 [17]. Globally, various Pvmdr-1 SNPs profiles including single (T958M; Y976F), double (T958M and F1076L; Y976F and F1076L), triple (T958M, Y976F, and F1076L), quadruple (S510T, M908L, T958M, and F1076L; S513R, M908L, T958M, and F1076L), quintuple (G689S, L845F, M908L, T958M, and F1076L), sextuple (S510T, G698S, M908L, T958M, Y976F, and F1076L; S513R, G698S, M908L, T958M, Y976F, and F1076L), and septuple (S513R, 1636T, G698S, M908L, T958M, Y976F, and F1076L; S513R, G698S, M908L, A829V, T958M, Y976,F and F1076L) centred on these mutations (T958M, Y976F, and F1076L). [21]. However, K44, L493, T529, and Y541C mutations in the Pvmdr-1 gene have not been reported.

Thus, we inferred rapid transition of polymorphisms in the Pvmdr-1 gene. Fortunately, there is no resistance in the abovementioned mutations due to chloroquine-induced normal clearance of the parasite. In detail, patients with Y $541 \mathrm{C}$ phenotypic mutation showed no resistance to chloroquine 
treatment, and parasitic clearance was confirmed after one month. Thus, the Y541C mutation is not related to chloroquine resistance.

In a previous study, Suwanarusk R. et al. showed the Y976F mutation to be linked to chloroquine resistance based on increase of $\mathrm{IC}_{50}$ value [18]. Our study showed no SNP at the Y976F position. In previous research, $\mathrm{F} 1076 \mathrm{~L}$ mutation was found in all samples with $\mathrm{Y} 976 \mathrm{~F}$ mutation and was regarded as a background mutation [19]. In cases of F1076L mutation, although Y976F mutation was not detected, these mutations observed in investigated all specimens [20]. Based on these results, consistent surveillance of Pvmdr-1 SNPs should be performed.

\section{Conclusions}

Unlike other countries, in malaria-endemic regions of ROK, a non-synonymous mutation profile (G698S, L845F, M908L, T958M, and F1076L) has prevailed. In this study, we investigated the types and frequency of PvmdrSNPs in the chemoprophylaxis-executed areas of ROK army and found various SNPs including quintuple mutations (G698S, L845F, M908L, T958M, and F1076L), Y541C, K44, L493, and T529. Although $P$. vivax resistance is unreported, novel and transitions of Pvmdr SNPs were verified. Therefore, consistent monitoring of chemoprophylaxis-linked Pvmdr-1 polymorphisms should be conducted to detect drug resistance against $P$. vivax in ROK soldiers.

\section{Abbreviations}

Pvmdr-1: Plasmodium vivax multidrug resistance 1; SNP: single nucleotide polymorphism; ROK: Republic of Korea; DMZ: Demilitarized zone, AFMC: Armed Forces Medical Command, PCR: Polymerase chain reaction; KCDA: Korea Disease Control and Prevention Agency.

\section{Declarations}

\section{Acknowledgements}

None

\section{Author's contributions}

KTN contributed in designing, drafting and finalization of the manuscript. WSL contributed in overall research implementation. JJB conceived the idea and participated on writing and the discussion. QEP conceived the idea and participated on the discussion. All authors read and approved the final manuscript.

\section{Funding}

This work was supported by the Internal Research Program from the Armed Forces Medical Research Institute of ROK (Fund code \#16-internal-1) 
Availability of data and materials

All data pertaining to this study are within the manuscript and the supporting file.

\section{Ethics approval and consent to participate}

This study was approved by the ethics committee of the Armed Forces Medical Command (AFMC) of the ROK (Approval No. AFMC-16067-IRB-16-056). Written informed consent was obtained from each participant.

\section{Consent for publication}

Not applicable

\section{Competing interests}

All authors declare that they have no competing interests.

\section{References}

1. Chai IH, Lim FI, YOON SN, Oh WI, Kim SJ, Chai JY. Occurrence of tertian malaria in a male patient who has never been abroad. Korean J Parasitol. 1994;32:195-200.

2. Yeom JS, Jun G, Kim JY, Lee WJ, Shin EH, Chang KS, et al. Status of Plasmodium vivax malaria in the Republic of Korea, 2008-2009: decrease followed by resurgence. Trans R Soc Trop Med Hyg. 2012;106:429-36.

3. Korea Centers for Disease Control and Prevention Infectious Disease Statistics System. http://is.cdc.go.kr.

4. Yeom JS, Ryu SH, Oh S, Choi DH, Song KJ, Oh YH, et al. Evaluation of anti-malarial effects of mass chemoprophylaxis in the Republic of Korea army. J Korean Med Sci. 2005;20707-12.

5. Lee SW, Lee M, Lee DD, Kim C, Kim YJ, Kim JY, et al. Biological resistance of hydroxychloroquine for Plasmodium vivax malaria in the Republic of Korea. Am J Trop Med Hyg. 2009;81:600-4.

6. Chung DI, Jeong S, Dinzouna-Boutamba SD, Yang HW, Yeo SG, Hong Y, et al. Evaluation of single nucleotide polymorphisms of pvmdr1 and microsatellite genotype in Plasmodium vivax from Republic of Korea military personnel. Malar J. 2015;14:336.

7. Schuurkamp GJ, Spicer PE, Kereu RK, Bulungol PK, Rieckmann KH. Chloroquine-resistant Plasmodium vivax in Papus New Guinea. Trans R Soc Trop Med Hyg. 1992;86:121-2.

8. Rieckmann KH, Davis DR, Hutton DC. Plasmodium vivax resistance to chloroquine. Lancet, 1989;2:1183-4.

9. Schwartz IK, Lackritz EM, Patchen LC. Chloroquine-resistant Plasmodium vivax from Indonesia. N Engl J Med. 1991;324:927. 
10. Baird JK, Chloroquine resistance in Plasmodium vivax. Antimicrob Agents Chemother. 2004;48:407583.

11. Ruebush TK 2nd, Zegarra J, Cairo J, Andersen EM, Green M, Pillai DR, et al. Chloroquine-resistant Plasmodium vivax malaria in Peru. Am J Trop Med Hyg. 2003;69:548-52.

12. Soto J, Toledo J, Gutierrez P, Luzz M, Llinas N, Cedeno N, et al. Plasmodium vivax clinically resistant to chloroquine in Colombia. Am J Trop Med Hyg. 2001;65:90-3.

13. Marlar-Than, Myat-Phone-Kyaw, Aye-Yu-Soe, Khaing-Khaing-Gyi, Ma-Sabai, Myint-Oo. Development of resistance to chloroquine by Plasmodium vivax in Myanmar. Trans R Soc Trop Med Hyg. 1995;89:307-8.

14. Njokah MJ, Kang'ethe JN, Kinyua J, Kariuki D, Kimani FT. In vitro selection of Plasmodium falciparum Pfcrt and Pfmdr1 variants by artemisinin. Malar J. 2016;15:381.

15. Joy S, Mukhi B, Ghosh SK, Achur RN, Gowda DC, Surolia N. Drug resistance genes: pvcrt-o and pvmdr-1 polymorphism in patients from malaria endermic South Western Coastal Region of India. Malar J. 2018;17:40.

16. Schousboe ML, Ranjitkar S, Rajakaruna RS, Amerasinghe PH, Morales F, Pearce R, et al. Multiple Origins of Mutations in the mdr1 Gene-A Putative Marker of Chloroquine Resistance in P. vivax. PLoS Negl Trop Dis. 2015;9:e0004196.

17. Parseai M, Raeisi A, Spotin A, Shahbazi A, Mahami-Oskouei M, Hazratian T, et al. Molecular evaluation of pvdhfr and pvmdr-1 mutants in Plasmodium vivax isolates after treatment with sulfadoxine/pyrimethamine and chloroquine in Iran during 2001-2016. Infect Genet Evol. 2018;64:7075.

18. Suwanarusk R, Chavchich M, Russell B, Jaidee A, Chalfein F, Barends M, et al. Amplification of pvmdr1 associated with multidrug-resistant Plasmodium vivax. J Infect Dis. 2008;198:1558-64.

19. Tacoli C, Gai PP, Siegert K, Wedam J, Kulkarni SS, Rasalkar R, et al. Characterization of Plasmodium vivax pvmdr1 Polymorphisms in Isolates from Mangaluru, India. Am J Trop Med Hyg. 2019;101:416417.

20. Barnadas C, Ratsimbasoa A, Tichit M, Bouchier C, Jahevitra M, Picot S, et al. Plasmodium vivax resistance to chloroquine in Madagascar: clinical efficacy and polymorphisms in pvmdr1 and pvcrt-o genes. Antimicrob Agents Chemother. 2008;52:4233-40.

21. Kittichai V, Nquitragool W, Ngassa Mbenda HG, Sattabongkot J, Cui L. Genetic diversity of the plasmodium vivax multidrug resistance 1 gene in Thai parasite populations. Infect Genet Evol. 2018;64:168-177.

\section{Tables}

Due to technical limitations, table 1, 2 and 3 is only available as a download in the Supplemental Files section. 
Figures

(a)

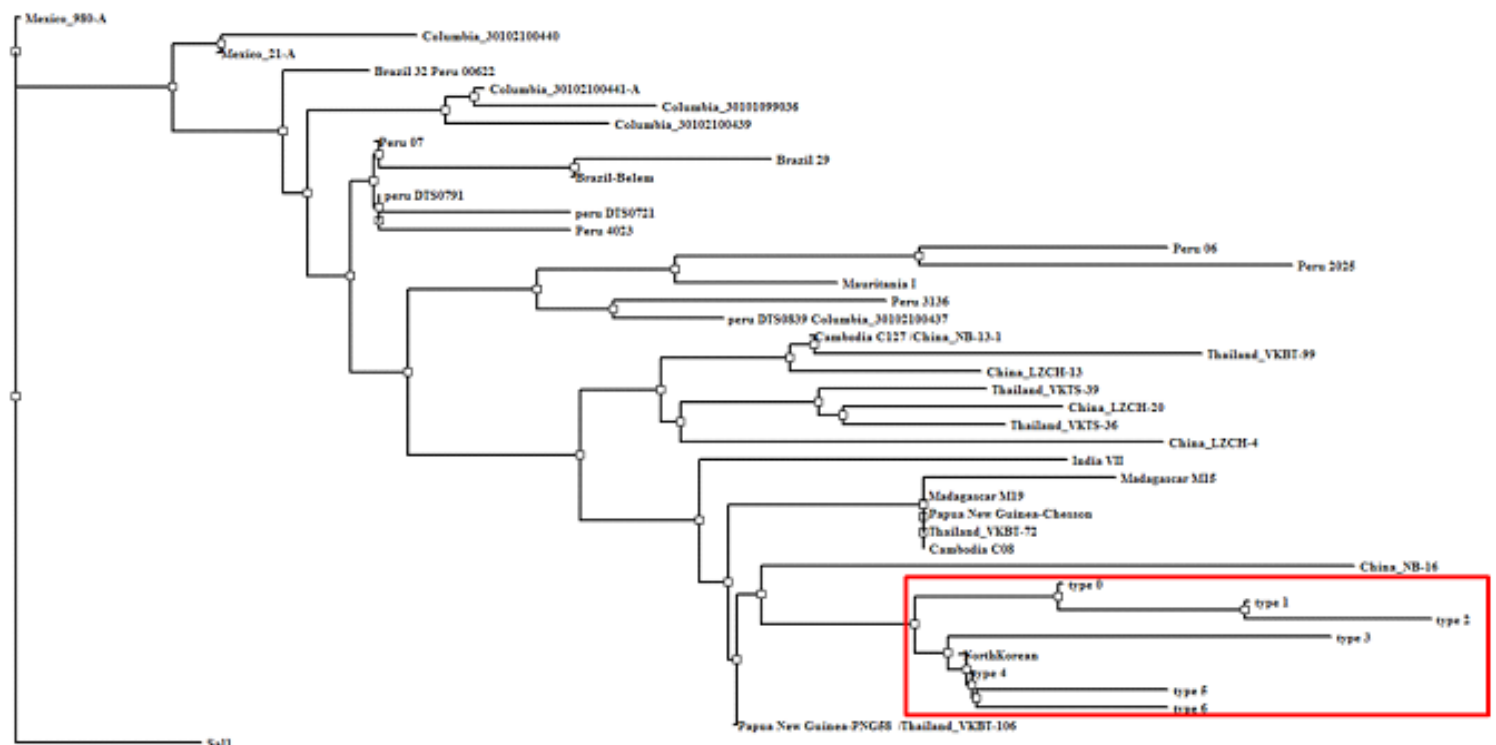

$\underline{0.0001}$

(b)

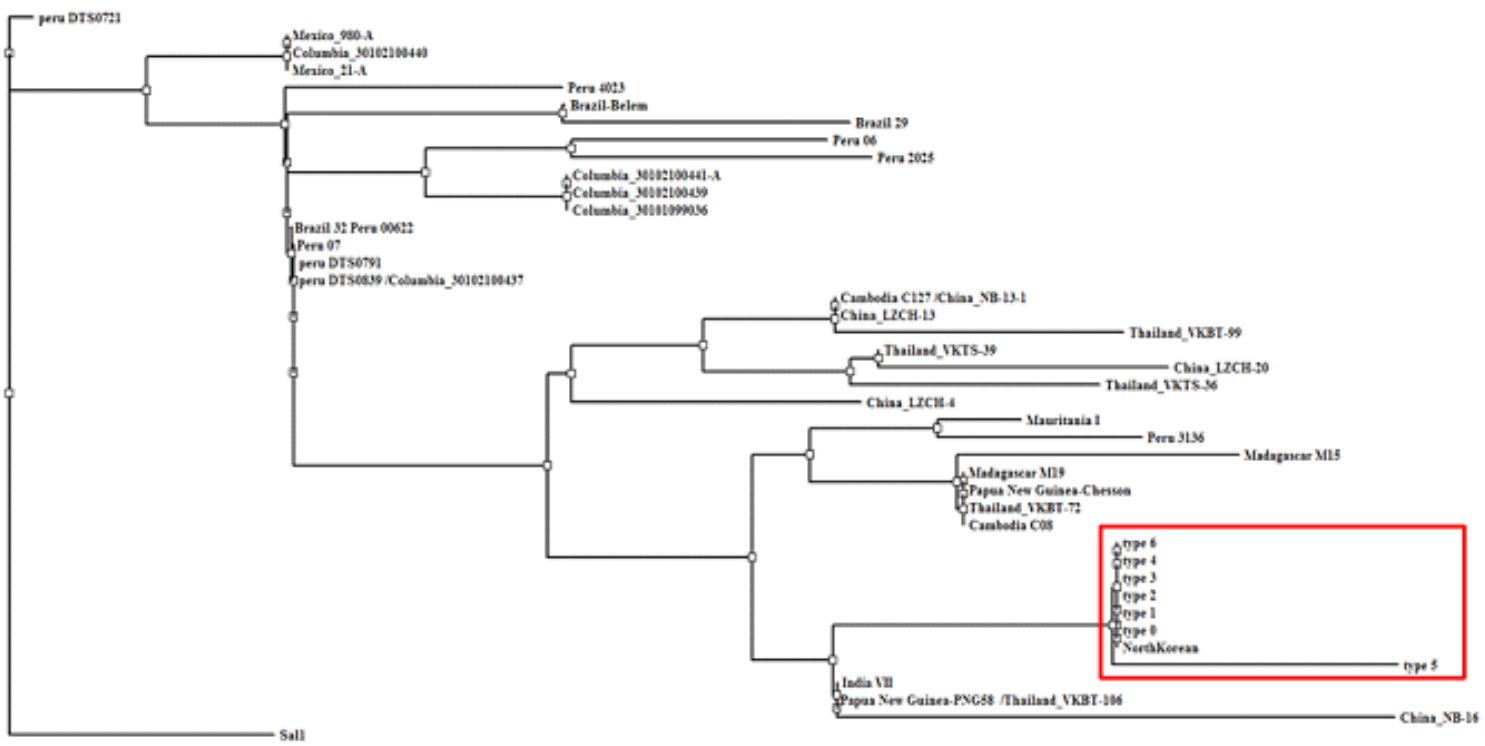

am

\section{Figure 1}

The phylogenetic analysis of Pvmdr-1 gene using neighbor-joining algorithm (Bio Edit software) (a) MDR nucleotide unrooted tree, (b) MDR amino acid unrooted tree. Phylogenetic analysis of Pvmdr-1 gene was 
generated using the neighbor-joining algorithm (Bio Edit software). The Sal I strain and global isolated parasite sequences of Plasmo DB (Plasmodb.org) were used as reference sequences.

\section{Supplementary Files}

This is a list of supplementary files associated with this preprint. Click to download.

- Supplementatyfigure1.20162017sequencealignmentdata.pptx

- Table.docx 